\title{
Location Evaluation of Childcare Facilities Focusing on Transportation in Japanese Urban Areas
}

\author{
Keisho Satoh1, Koya Tsukahara ${ }^{2 *}$, Kayoko Yamamoto ${ }^{2}$ \\ ${ }^{1}$ Department of Informatics and Engineering, University of Electro-Communications, Tokyo, Japan \\ ${ }^{2}$ Graduate School of Informatics and Engineering, University of Electro-Communications, Tokyo, Japan \\ Email: ^t1730063@edu.cc.uec.ac.jp
}

How to cite this paper: Satoh, K., Tsukahara, K. and Yamamoto, K. (2018) Location Evaluation of Childcare Facilities Focusing on Transportation in Japanese Urban Areas. Journal of Geographic Information System, 10, 521-538.

https://doi.org/10.4236/igis.2018.105028

Received: September 27, 2018

Accepted: October 22, 2018

Published: October 25, 2018

Copyright $(9) 2018$ by authors and Scientific Research Publishing Inc. This work is licensed under the Creative Commons Attribution International License (CC BY 4.0).

http://creativecommons.org/licenses/by/4.0/

\begin{abstract}
In recent Japan, as there has been an increase of dual-income households and the demand for childcare facilities has especially increased especially in urban areas, childcare facilities and workers are lacking and it leads to the serious issue of children on waiting lists. Based on the background mentioned above, using statistical method, geographical information system (GIS) and public open data, scenario analysis to select transportation, the present study aimed to propose a method to quantitatively evaluate the current location of childcare facilities in Japanese urban areas. In the present study, the model of the $p$-median problem used to obtain the optimal location of facilities was modified, and a method to evaluate the current situation concerning the shortage or overage of childcare facilities by district was proposed. As evaluations are conducted using quantitative data such as the specialization coefficient of person trip for transportation and the distance between childcare facilities and districts, the evaluation results are also quantitative, making it an effective indicator for evaluating the locations of childcare facilities. Additionally, the specialization coefficient of person trip for transportation and the distance between childcare facilities and districts were calculated based on public open data. Therefore, the evaluation method in the present study has a high temporal reproducibility as well as spatial reproducibility.
\end{abstract}

\section{Keywords}

Childcare Facility, Transportation, Person Trip, P-Median Problem, Statistical Method, GIS (Geographic Information Systems), Public Open Data, Scenario Analysis 


\section{Introduction}

In recent years, there has been an increase of dual-income households in Japan, and the demand for childcare facilities has especially increased in urban areas. Therefore, childcare facilities and workers are lacking, resulting in the serious issue of children on waiting lists. According to the Report on the Situation Related to Nursery Schools (2017) by the Ministry of Health, Labour and Welfare (MHLW) [1], the number of waitlisted children was 26,175 in 2010 and 26,081 in 2017, indicating the ongoing lack of childcare facilities. Though subsidy is granted for the construction of childcare facilities, childcare facilities cannot be greatly increased as there is a limit to the amount of subsidy. Therefore, when constructing new childcare facilities, it is essential to place priority on districts lacking such facilities. In order to do so, it is necessary to evaluate current locations to extract districts lacking facilities. Furthermore, as there are various types of facilities, certain characteristics can be seen in the location method according to each type. For childcare facilities, the distribution of facilities should not be concentrated in specific districts but rather arranged in locations where all who need to use them can fairly do so.

Based on the above, using statistical method, geographical information system (GIS) and public open data, and focusing on the transportation of guardians to childcare facilities, the present study aims to propose a method to quantitatively evaluate the current location of childcare facilities in Japanese urban areas. The present study will conduct a scenario analysis accurately reflecting the transportation of guardians to childcare facilities in order to evaluate the location of such facilities, and the evaluation results will be visualized on digital maps using GIS. Based on such results, districts lacking childcare facilities will be extracted. By means of the above, when planning the construction of a new childcare facility, beneficial information can be provided for selecting candidate sites.

For the purpose of the present study, first of all, section 2 will introduce the preceding studies in the related fields and demonstrate the originality. Next, section 3 will show the framework and method of evaluation, and section 4 will select the evaluation target area and introduce the data processing. Base on the results of the previous sections, section 5 will evaluate the current location of childcare facilities and extract districts lacking the facilities in the evaluation target area. Finally, section 6 will conclude the results of the present study and summarize future research subjects.

\section{Related Work}

The present study is related to 1) studies concerning the location of childcare facilities, 2) studies concerning the facility location issues and 3) studies concerning transportation to childcare facilities. The following will introduce the major preceding studies in the above three study areas, and discuss the originality of the present study in comparison with the others. Though the preceding studies in 1) focused on childcare facilities to evaluate their locations, the ones in 2) 
handled the facility location issues selecting the targets among both private and public facilities other than childcare facilities. As the issues related to childcare facilities are tremendously serious in Japanese urban areas, there are a lot of preceding studies in 1) 3) especially in recent Japan.

Regarding 1) studies concerning the location of childcare facilities, Umezawa et al. (2003) [2] grasped the utilization analysis of childcare facilities and proposed an optimum location plan in Japanese metropolitan areas. Kukimoto et al. (2012) [3] described a conflict occurred between the local childcare culture and the central government policy regarding childcare facilities in Okinawa, Japan. Segawa et al. (1996) [4] and Sakaki et al. (2014) [5] focused on the transportation and commute of guardians and evaluated the location of childcare facilities in Japanese urban areas. Fuse et al. (2013) [6] proposed the possibility of reconstructing supplementary-term facilities using vacant classrooms of elementary schools in Tokyo, Japan. Furumido et al. (2015) [7] focused on the transportation of guardians, satisfaction levels concerning transportation, as well as views on child-rearing, and made suggestions concerning the transportation system and childcare facilities in Osaka, Japan. Arami (2017) [8] examined the relationship between the local governments and the services provided by childcare facilities in recent Japan. Langford et al. (2018) [9] compared the spatial distribution of providers with that of potential demand arising from working parents targeted in the childcare offer in Welsh, by drawing on Geographic Information System network models.

As for 2) studies concerning the facility location issues, Nagashima et al. (2014) [10] used the mean-field approximation to propose an algorithm to derive the optimum location for Electric Vehicle (EV) power supply stands. Ozgen et al. (2014) [11] combined a two-phase possibilistic linear programming approach and a fuzzy analytical hierarchical process approach to optimize two objective functions (minimum cost and maximum qualitative factors benefit) in a four-stage (suppliers, plants, distribution centers and customers) supply chain network in the presence of vagueness. Munemasa et al. (2015) [12] proposed a method to derive the optimum solution for the minimization issue of transportation costs using the linear relaxation method for the urban model made up of business and residential areas. Tanaka et al. (2015) [13] applied the Quintile Share Ratio (QSR), which is an indicator for the degree of income inequality, to the facility location analysis of linear cities. Additionally, Tanaka et al. (2016) [14] used the Median Share Ratio (MSR), which is an equitability indicator based on the QSR, to construct a facility location evaluation model with 1 or 2 facilities in the linear cities where there is a uniform distribution of the population. Furuta et al. (2017) [15] used the more generalized the QSR to propose an optimum solution for multiple-facility location in cases where the demand and facility location of candidate sites are discretely distributed. Tsukahara et al. (2017) [16] proposed a method to evaluate the location of nursing facilities in Tokyo, Japan, improving the MSR which was applied to a linear city in Tanaka 
et al. $(2015,2016)$ [13] [14].

Zhang et al. (2016) [17] investigated a facility location problem incorporating service competition and disruption risks, developing a new binary bilevel linear programming (BBLP) model. Ohdate et al. (2017) [18] considered relocation of facilities for the management of public facilities, categorized them based on building, function and location to create an evaluation method for them. Nagai et al. (2017) [19] proposed an agent-based urban model in which the relationship between a central urban area and a suburban area was simply expressed. Usui et al. (2018) [20] theoretically investigated the relationship between the continuous walking distance distribution and the density of resting places.

For 3) studies concerning transportation, Tahara et al. (2008) [21] grasped the distance between the workplaces and houses of guardians can have a great effect on the transportation range to childcare facilities in Japanese metropolitan areas. Takahashi (2011) [22] conducted utilization and consciousness surveys on guardians in Nagano, Japan, and revealed that users of nursery schools place importance on the accessibility to their house while users of kindergartens focus more on the expenses and services provided. Grengs (2011) [23] proposed a method for deriving nonwork accessibility indicators and evaluated how nonwork accessibility to socio-economic facilities including childcare facilities varies among social groups in the Detroit metropolitan region. Thakuriah et al. (2011) [24] analyzed the employment transportation services for the Job Access and Reverse Commute (JARC) program between job-training centers and childcare facilities in the U.S. Tatsumi et al. (2012) [25] and Izumi et al. (2012) [26] revealed the characteristics of transportation to childcare facilities for dual-income households in Japanese metropolitan areas. Ohmori (2015) [27] discussed the types of cities and transportation environments required for increasing quality of life (QOL) of child-rearing households in Japan.

Regarding studies related to 1), though Segawa et al. (1996) [4], Sakaki et al. (2014) [5] and Furumido et al. (2015) [7] focused on the transportation of guardians, only the needs on a small spatial scale were grasped and evaluations reflecting the details of transportation were not conducted. In studies related to 2), Nagashima et al. (2014) [10] and Munemasa et al. (2015) [12] respectively focused on the efficient location of EV power supply stands and working and housing distribution, and proposed a method to derive the optimum solution. Additionally, though Tanaka et al. $(2015,2016)$ [13] [14] and Furuta et al. (2017) [15] proposed the methods to evaluate facility location focusing on equitability, they were only applied to virtual cities and not to actual cities. Tsukahara et al. (2017) [16] referred to these studies to propose a new method to evaluate the location of nursing facilities in actual cities.

Therefore, with the results of the preceding studies of 1) 2) as a foundation, the present study will use the findings of 3) as a reference to demonstrate the originality by quantitatively evaluating current locations of childcare facilities. The present study will apply the transportation of guardians to the scenario 
analysis to accurately calculate the time spent on transportation. Furthermore, with current location of childcare facility as a premise, realistic and effective information can be provided for evaluations of appropriate location when considering the construction of new facilities.

\section{Framework and Method of Evaluation}

\subsection{Framework and Process of Evaluation}

The ArcGIS Pro Ver.2.0 of Environmental Systems Research Institute (ESRI) will be used for the evaluation method of location of childcare facility. The evaluation framework and process are as shown below. The flow of the framework and process of evaluation in the present study is shown in Figure 1.

1) Creating the distribution maps of infants and toddlers, childcare facilities and transportation facilities

The distribution maps of infants and toddlers, childcare facilities and transportation facilities (train stations and bus stops) by each district (made up of streets and towns) will be created in digital map format using GIS.

2) Calculating the linear distance between each district and each childcare facility

Using the distribution map of childcare facilities created in 1), the distance between the center of each district and each childcare facility will be calculated.

3) Calculating the transportation time according to each transportation method

Using the distribution maps of childcare facilities and transportation facilities created in 1), and the linear distance between each district and each childcare facility calculated in 2), transportation time will be calculated in each district, based on travel speed and distance according to the transportation method.

4) Selecting a transportation method using a scenario analysis

Considering the results of 3), possible transportation method will be selected in each district.

5) Creating the distribution map of the composition ratio of person trips

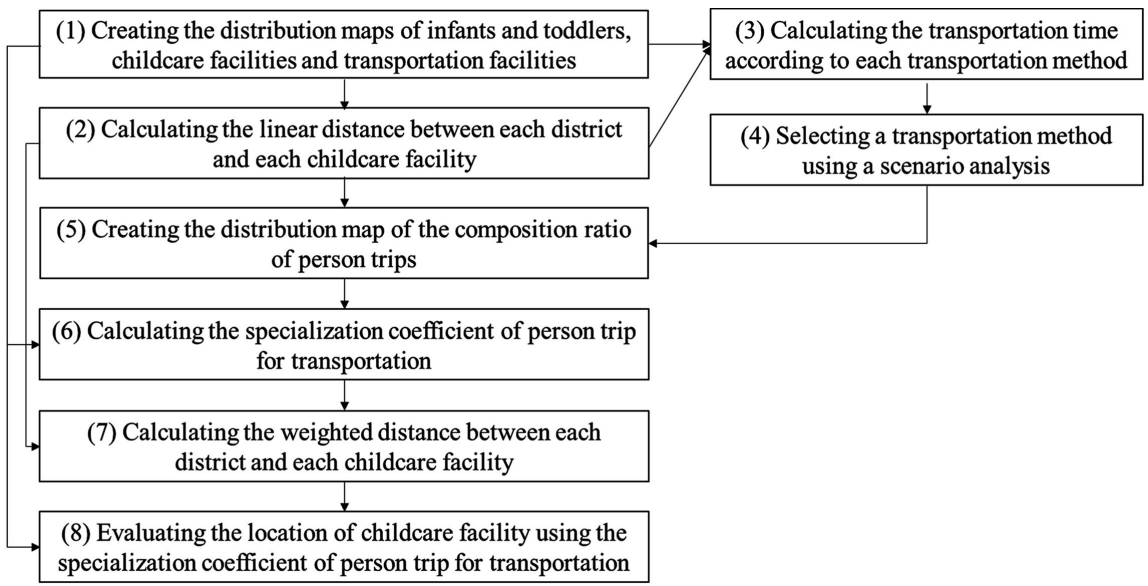

Figure 1. Flow of framework and process of evaluation. 
Based on the results of 4 ), the distribution map of the composition ratio of person trips by each district will be created in digital map format using GIS.

6) Calculating the specialization coefficient of person trip for transportation

Using the distribution maps of infants and toddlers, and the composition ratio of person trips created in 1) 5), the specialization coefficient of person trip for transportation will be calculated in each district. In the present study, the specialization coefficient of person trip for transportation is defined as an indicator that clearly shows the characteristics of person trip of each transportation method to childcare facilities mainly include traveling on foot, car, bicycle, train and bus by each district.

7) Calculating the weighted distance between each district and each childcare facility

Adding the specialization coefficient of person trip for transportation obtained in 6) to the linear distance between each district and each childcare facility obtained in 2), the weighted distance will be calculated in each district.

8) Evaluating the location of childcare facility using the specialization coefficient of person trip for transportation

Using the distribution map of the number of infants and toddlers created in 1) as well as the weighted distance between each district and each childcare facility calculated in 7), the evaluation points for each district will be calculated.

\subsection{Setting Selection Conditions for Transportation Methods}

Transportation methods to childcare facilities mainly include traveling on foot, car, bicycle, train and bus. Suzuki et al. (2015) [28] conducted questionnaire surveys on the transportation time for those who use childcare facilities, and the average transportation time for all methods was 10 minutes.

Therefore, transportation time in the present study will be set as 10 minutes or less. Transportation time for each method in each district will be calculated, and if it is 10 minutes or less, the method will be valid, whereas if it is more than 10 minutes, the transportation method will be considered invalid. Additionally, meeting the requirements above, transportation using cars will only be possible if the childcare facility has a parking area. Moreover, with transportation by train and bus, the closest train station or bus stop from each district and each childcare facility will be used.

Though many facilities usually care for infants and toddlers from 7 a.m. to 7 p.m., there is an increase of childcare facilities that extend this time in consideration of guardians who work overtime. Therefore, in the present study, the commute time to childcare facilities will be 7-10 a.m. and the pick-up time will be 6 - 9 p.m.

\subsection{Evaluation Method}

\subsubsection{Creating the Distribution Maps of Infants and Toddlers, Childcare Facilities and Transportation Facilities}

1) Distribution map of infants and toddlers 
The present study will set the age of infants and toddlersaged 0 - 4 as the target of those going to childcare facilities. For the evaluation target area, as evaluation points will be calculated according to each district, the distribution map of infants and toddlers by the district will be created in digital map format using GIS.

2) Distribution map of childcare facilities

The distribution map of childcare facilities will be created in digital map format using GIS. Though childcare facilities include nursery schools, kindergartens and other related facilities, the present study will only target nursery schools and kindergartens.

3) Distribution map of transportation facilities

The distribution map of train stations and bus stops will be created in digital map format using GIS. The distribution map of train stations and bus stops will be used to calculate the transportation time by train and bus.

\subsubsection{Calculating the Distance between Each District and Each Childcare Facility}

As for the distance between each district and each childcare facility, the linear distance will be calculated first. Then, by estimating the road distance from the linear distance, the transportation time for each method will be calculated. The linear distance between each district and each facility can be calculated using Equation (1).

$$
d=r \times \arccos \left(\sin y_{1} \sin y_{2}+\cos y_{1} \cos y_{2} \cos \left(x_{1}-x_{2}\right)\right)
$$

d: Linear distance $(\mathrm{m})$;

$r$. Radius of the earth $(6,378,137 \mathrm{~m})$;

$y_{1}$ : Latitude of facility $;$

$y_{2}$ : Latitude of district $i$

$x_{1}$ : Longitude of facility $j ;$

$x_{2}$ : Longitude of district $i$.

\subsubsection{Calculating the Transportation Time for Each Transportation Method}

In order to determine whether each transportation method shown in section 3.2 is actually possible, the transportation time for each method will be calculated using the following method.

1) On foot

Transportation on foot will be calculated by the road distance and walking speed. Segawa et al. (1996) [3] set $4 \mathrm{~km} / \mathrm{h}$ for the walking speed for adults only and $3 \mathrm{~km} / \mathrm{h}$ for adults walking with infants and toddlers in order to calculate the transportation time. Additionally, Marinrique Ruiz (2013) [29] demonstrated that the road distance of narrow roads that are only passable for those on foot is 1.271 times longer than the linear distance, and the road distance of wide roads that are drivable is 1.415 times longer than the linear distance. Accordingly, in the present study, transportation time on foot will be calculated by setting the transportation speed as $3 \mathrm{~km} / \mathrm{h}$ while the road distance will be set as 1.271 times 
longer than the linear distance.

2) Bicycle

Transportation time by bicycle will be calculated by the road distance and the travel speed on a bicycle. According to Suzuki et al. (2015) [28], though the average speed of bicycles is usually around $11-15 \mathrm{~km} / \mathrm{h}$, the transportation time with $10 \mathrm{~km} / \mathrm{h}$ as the speed when cycling with infants and toddlers. The present study will calculate the transportation time by setting the transportation speed as $10 \mathrm{~km} / \mathrm{h}$ for bicycles and the road distance as 1.415 times longer than the linear distance.

3) Car

Transportation time by car will be calculated by the road distance and the travel speed of cars. Yabe et al. (2016) [30] grasped the current situation of road network with $21.3 \mathrm{~km} / \mathrm{h}$ as the average speed of cars in Tokyo. Accordingly, the present study will calculate the transportation time for cars by setting the transportation speed as $21.3 \mathrm{~km} / \mathrm{h}$ and the road distance as 1.415 times longer than the linear distance.

4) Train

Transportation time by train will be calculated from the sum of the transportation time on foot between districts and train stations, the transportation time on the train, and the transportation time on foot between the childcare facility and the train station.

5) Bus

Transportation time by bus will be calculated from the sum of the transportation time on foot between district $i$ and the bus stop, the transportation time on the bus, and the transportation time on foot between childcare facility $j$ and the bus stop.

\subsubsection{Selecting a Transportation Method Using a Scenario Analysis}

A scenario will be created based on the transportation time according to each method calculated in the previous section, and the transportation time slot and method for each district will be selected using a scenario analysis. The flow of the scenario analysis in the present study is shown in Figure 2.

\subsubsection{Creating a Distribution Map of the Composition Ratio of Person Trips}

Based on the transportation method selected in the previous section, the distribution map of the composition ratio of person trips will be created. To calculate evaluation points of evaluation target area according to each district, the present study will calculate person trips in each district and display the result on the digital map of GIS. The person trip data, which will be described in detail in the next section, is the data of each region which is a group of several districts. Therefore, using the ratio of the population of the entire region and that of each district, person trips for each district will be calculated and displayed on the digital map of GIS. 


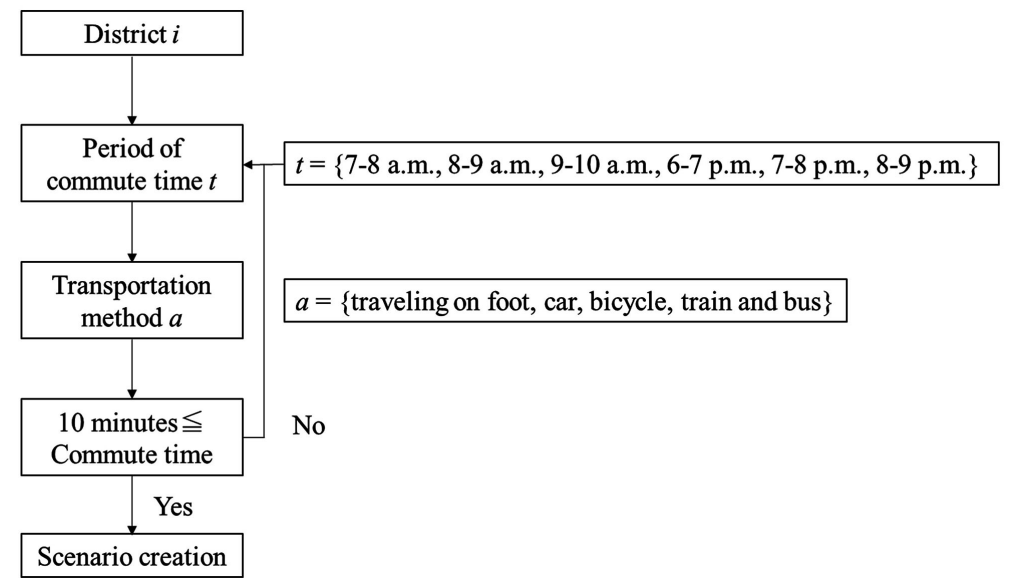

Figure 2. Flow of scenario analysis when selecting a transportation method.

\subsubsection{Calculating the Specialization Coefficient of Person Trip for Transportation}

Based on the definition in section 3.1, the specialization coefficient of person trip for transportation of each district is calculated. In order to calculate the specialization coefficient, the composition ratio of person trips for transportation in district $i$ will be calculated using Equation (2). The composition ratio of person trips for transportation in the entire evaluation target district will be calculated using Equation (3). By using these equations, the specialization coefficient of person trip for transportation can be calculated using Equation (4).

$$
R_{i}=\frac{P T_{k t a}}{P T_{k}} \times \frac{w_{i}}{w_{k}} \times \frac{w_{i} x}{p_{i}} \times 100
$$

$R_{i}$ : Composition ratio of person trips for transportation in district $i(\%)$.

$P T_{k t a}$ : Person trips of transportation method a, in district $k$ which is a group of several districts, and $t$ period of commute time $t$ (persons).

$P T_{k}$ : Total of all person trips in region $k$, which is a group of several districts (persons).

$w_{i}$ : Number of infants and toddlers aged 0 - 4 in district $i$ (persons).

$w_{k}$ : Number of infants and toddlers aged $0-4$ in region $k$, which is a group of several districts (persons).

$x$ : Number of guardians (persons).

$p_{i}$ : Total population of district $i$ (persons).

$$
R=\frac{P T_{t a}}{P T} \times \frac{w x}{p}
$$

$R$ : Composition ratio of person trips in the entire evaluation target area (\%).

$P T_{t a}$ : Person trips of transportation method $a$ and period of commute time $t$ in the entire evaluation target area (persons).

$P T$ : Total of all person trips in the entire evaluation target area (persons).

$w$ : Number of infants and toddlers aged $0-4$ in the entire evaluation target area (persons).

$x$ : Number of guardians (persons). 
$p$ : Total population of the entire evaluation target area (persons).

$$
S C_{i}=\frac{R_{i}}{R}
$$

$S C_{i}$ : specialization coefficient of person trip in district $i$.

$R_{i}$ : Composition ratio of person trips in district $i(\%)$.

$R$ : Composition ratio of person trips in the entire evaluation target area (\%).

\subsubsection{Calculating the Weighted Distance between Each District and Each Childcare Facilities}

In the present study, the distance between each district and each childcare facility will be weighted to become longer for districts with a higher specialization coefficient of person trip for transportation, and shorter for districts with a lower specialization coefficient of person trip for transportation. This is because the transportation for guardians with infants and toddlers among crowds is a great burden for both the guardian and child, the psychological transportation distance will seem longer compared to the road distance.

Regarding the weighted coefficient, the specialization coefficient of person trip for transportation calculated in the previous section will be used. The specialization coefficient is the value indicating the difference of person trips for the transportation of a certain district in comparison with other districts. Additionally, as the value of the specialization coefficient does not become excessively high or low, it is suitable for the weighted coefficient.

\subsubsection{Evaluating the Location of Childcare Facility Using the Specialization Coefficient of Person Trip for Transportation}

The $p$-median problem, which is one of the facility location problems, places facilities by minimizing the total sum of the distance from users to their nearest facility, and can be modeled as shown in Equation (5). This model derives the optimum location that lessens the load for users in all districts as much as possible by changing $X i j$.

$$
\min _{\mathrm{x} i j} Z=\sum_{i} \sum_{j} w_{i} d_{i j} X_{i j}
$$

$X_{i j} \in\{0,1\}$ : Allocation for facility $j$ in district $i$.

$w_{i}$ : Demand in district $i$.

$d_{i j}$ : Distance from districtito facility $j$.

The present study will propose an evaluation method based on the p-median problem. Equation (5) is a model that derives the optimum location that lessens the transportation load for users in all districts as much as possible, which is not the purpose of the present study. Therefore, in accord with the purpose of the present study, Equation (5) will be changed to Equation (6).

$$
\min _{d_{i j}} Z_{i}=w_{i} d_{i j}
$$

$Z_{i}$ : Evaluation points for district $i$.

$w_{i}$ : Demand in district $i$.

$d_{i j}$ : Distance from district $i$ to facility $j(\mathrm{~m})$. 
The facility location will be left unchanged by removing $X i j$ from Equation (5), and current location of childcare facility in each district can be quantitatively grasped by calculating evaluation points for each district. Moreover, the originality of the present study will be demonstrated in the weighted distance dij by the specialization coefficient of person trip for transportation as mentioned in section 3.2.2. The weighted distance will be indicated as Dij, and Equation (6) will be expressed as in Equation (7).

$$
Z_{i}=w_{i} D_{i j}
$$

$Z_{i}$ : Evaluation points for district $i$.

$w_{i}$ : Demand in district $i$.

$D_{i j}$ : Weighted distance from district $i$ to facility $j(\mathrm{~m})$.

The infant population and the weighted distance to childcare facilities for each district obtained in this section will be applied to Equation (7), the evaluation points of each district will be calculated, and calculation results will be displayed on digital maps using GIS.

\section{Selection of Evaluation Target Area and Data Processing}

\subsection{Selection of Evaluation Target Area}

In the present study, Chofu City, Tokyo is selected as the evaluation target area. As shown in Figure 3, Chofu City is located in the suburban region of Tokyo. In Chofu City, despite a recent increase in childcare facilities, there is also an increase in wait-listed infants and toddlers. Additionally, according to the survey on nursing schools in Chofu City [31], the number of wait-listed infants and toddlers in Chofu City was 208 in 2016, which was the highest number among the 10 neighboring cities. Taking this into consideration, the present study will conduct evaluations in the unit of 105 districts within Chofu City.

\subsection{Data Processing}

\subsubsection{Data Overview}

The utilized data and the utilization method of the data in the present study are shown in Table 1.

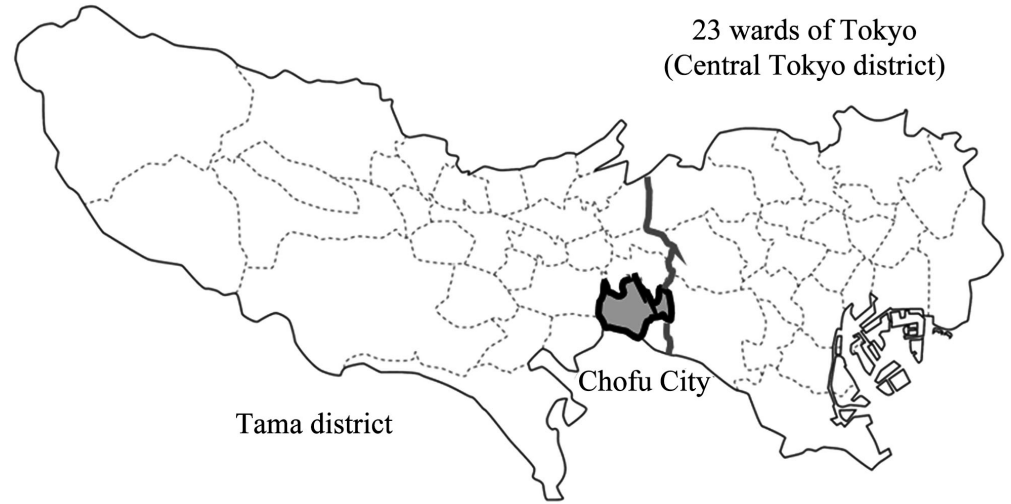

Figure 3. Location of Chofu City in Tokyo. 
Table 1. List of utilized data.

\begin{tabular}{|c|c|}
\hline Utilized data & Utilization method of data \\
\hline $\begin{array}{l}\text { Population by age } \\
\text { (National Census } 2010 \text { by the Statistics Bureau) }\end{array}$ & $\begin{array}{l}\text { Creating the distribution mapof infants and } \\
\text { toddlers }\end{array}$ \\
\hline $\begin{array}{l}\text { Traffic concentration in different time zones } \\
\text { for departure and arrival according to the } \\
\text { transportation method in each zone } \\
\text { (Person Trip Survey by the Tokyo Traffic } \\
\text { Planning Council) }\end{array}$ & $\begin{array}{l}\text { Creating the distribution map of the } \\
\text { composition ratio of person trips for } \\
\text { transportation and the calculating of } \\
\text { specialization coefficients of person trip for } \\
\text { transportation }\end{array}$ \\
\hline $\begin{array}{l}\text { Kodawari Navi forNursery schools and } \\
\text { Kindergartens }\end{array}$ & $\begin{array}{l}\text { Creating the distribution map of childcare } \\
\text { facilities }\end{array}$ \\
\hline Mapion & $\begin{array}{l}\text { Creating the distribution map of train stations } \\
\text { and bus stops }\end{array}$ \\
\hline
\end{tabular}

\subsubsection{Distribution Maps of Infants and Toddlers, Childcare Facilities and} Transportation Facilities

The distribution of infants and toddlers is shown in Figure 4, childcare facilities in Figure 5, and transportation facilities in Figure 6. As shown in Figure 6, there are districts with a high number of infants and toddlers excluding the north. As mentioned in section 3.2.1, nursery schools and kindergartens are shown in Figure 5, and such facilities are distributed throughout the entire Chofu City excluding the northern area. As evident in Figure 5, there are nursery schools and kindergartens within a reasonable commuting distance that are located outside Chofu City. Figure 6 shows the distribution of train stations and bus stops, and while the train lines travel through the city center, bus stops are distributed evenly throughout the city.

\subsubsection{Distribution Map of the Composition Ratio of Person Trips}

The person trip data is the data of each region which is a group of several districts. Using the method shown in section 3.3.6, the composition ratio of person trips by district is calculated and displayed on digital maps using GIS as shown in Figure 7.

\section{Evaluation}

\subsection{Evaluation for Case with the Specialization Coefficient}

Figure 8 is the evaluation results with the specialization coefficient of person trip for transportation. Districts with especially high evaluation points are outlined by light blue lines. As evident in Figure 8, evaluation points were high in districts that were indicated in section 4.2.2 to have a high population of infants and toddlers. Additionally, the northern districts of Chofu City had overall low evaluation points.

\subsection{Evaluation for Case without the Specialization Coefficient}

Figure 9 is the evaluation results without using specialization coefficient of person trip for transportation. Similar to Figure 8, districts with high evaluation 
points are outlined by light blue lines, and 3 out of all the outlined districts were the same as those outlined in Figure 8.

\subsection{Comparison and Consideration of the Evaluation Results with and without the Specialization Coefficient}

Figure 10 shows the difference between the evaluation results with and without the use of the specialization coefficient of person trip for transportation. Districts with evaluation points higher in the former results are red, while districts with points higher in the latter are blue. Additionally, districts with an especially large or small difference are outlined in light blue. Districts with high evaluation points without the use of specialization coefficients shown in Figure 8 had an even higher evaluation result with the use of specialization coefficients, highlighting the lack of childcare facilities. There were 15 districts that were blue and 52 districts that were red, indicating that the evaluation points were generally lower for evaluation results with the use of specialization coefficients.
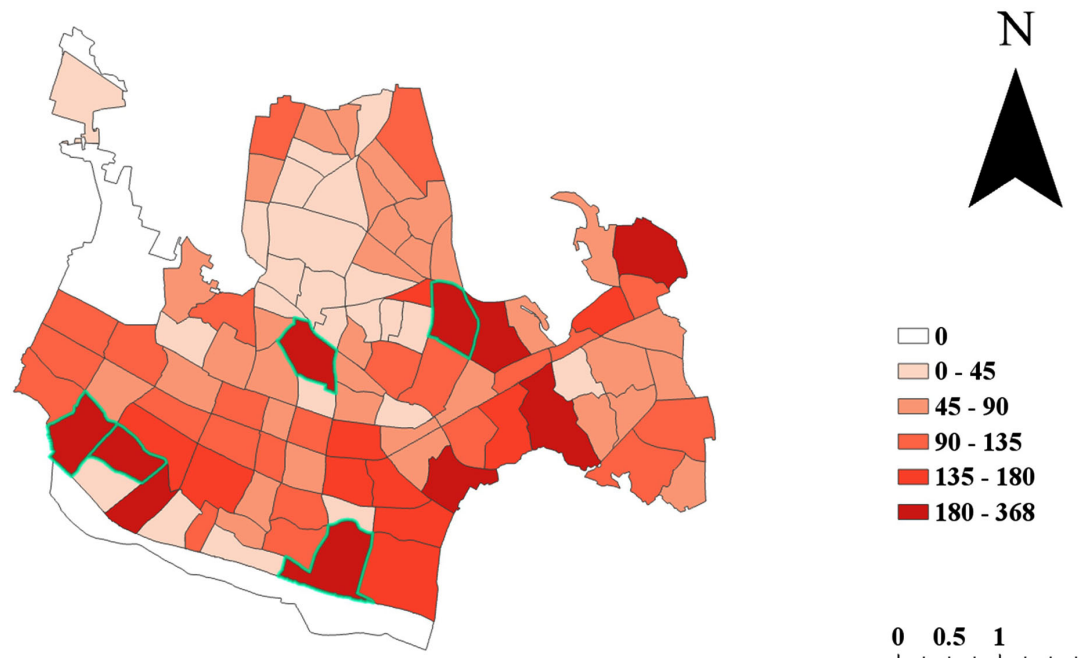

Figure 4. Distribution map of infants and toddlers aged 0 - 4 (persons).

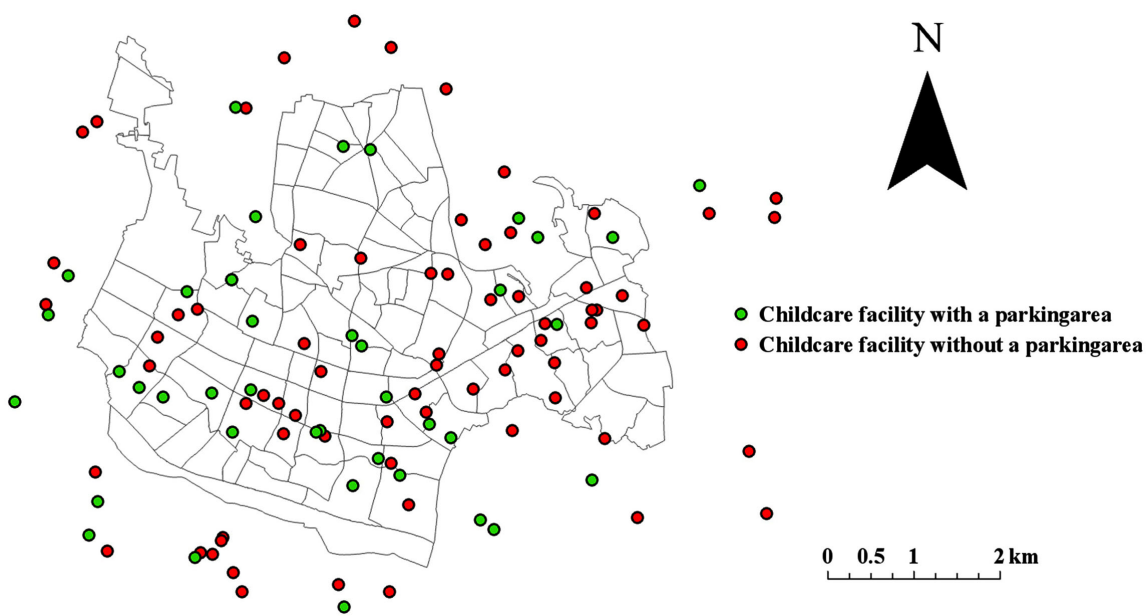

Figure 5. Distribution map of childcare facilities. 

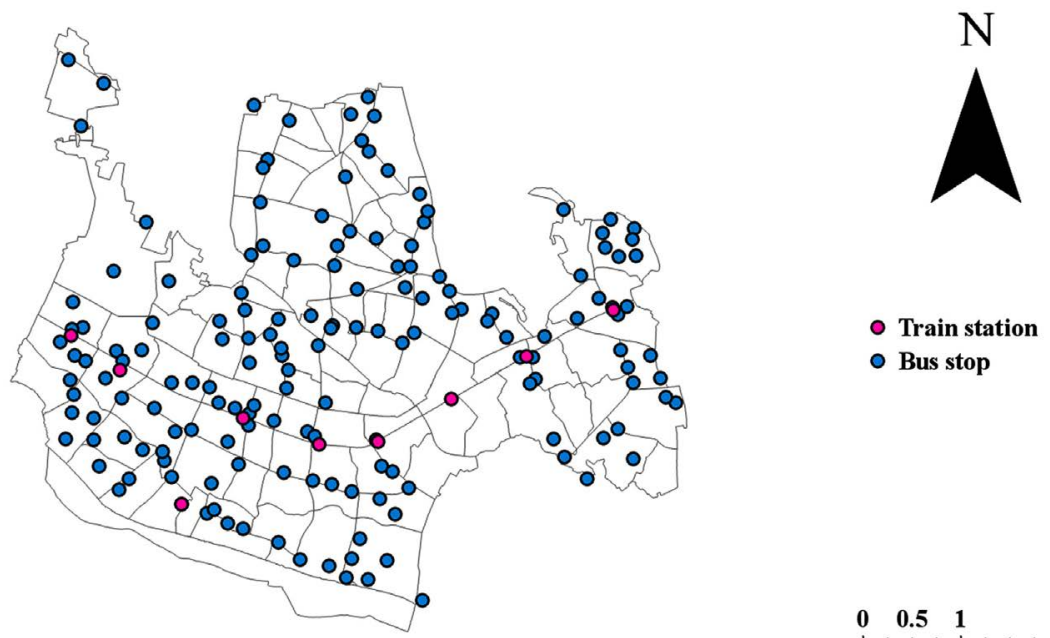

- Bus stop

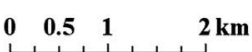

Figure 6. Distribution map of transportation facilities.
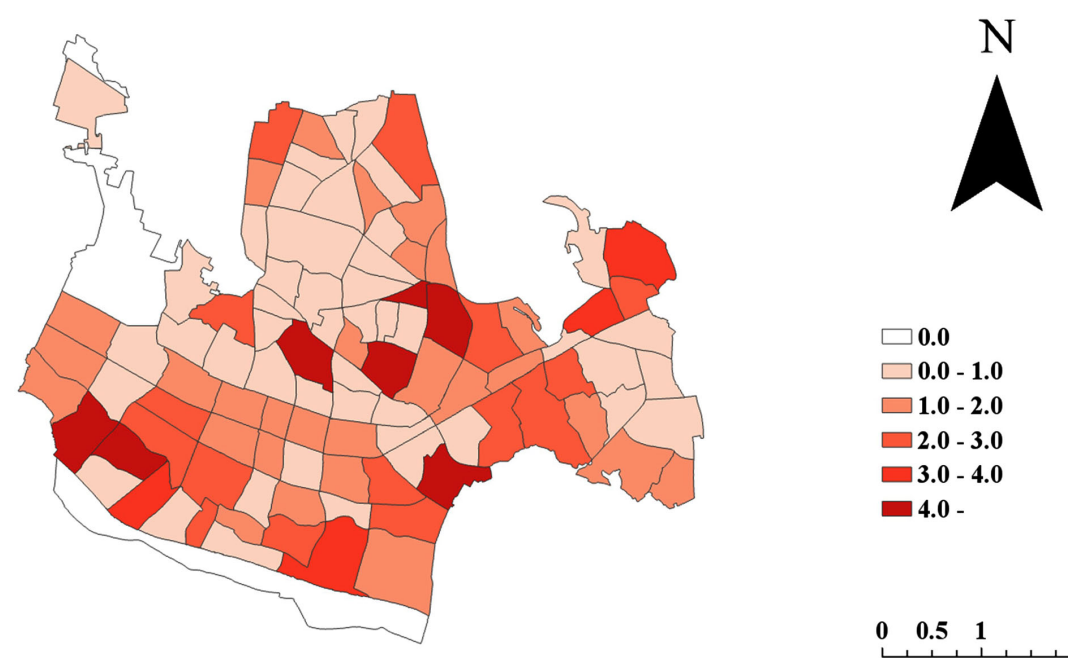

$$
\begin{aligned}
& \square 0.0 \\
& \square 0.0 \text { - } 1.0 \\
& \square 1.0 \text { - 2.0 } \\
& \square 2.0 \text { - 3.0 } \\
& \square 3.0 \text { - } 4.0 \\
& \square 4.0 \text { - }
\end{aligned}
$$

$\begin{array}{lll}0 & 0.5 & 1\end{array}$ $2 \mathrm{~km}$

Figure 7. Distribution map of composition ratio of person trips for transportation in Chofu City (\%).
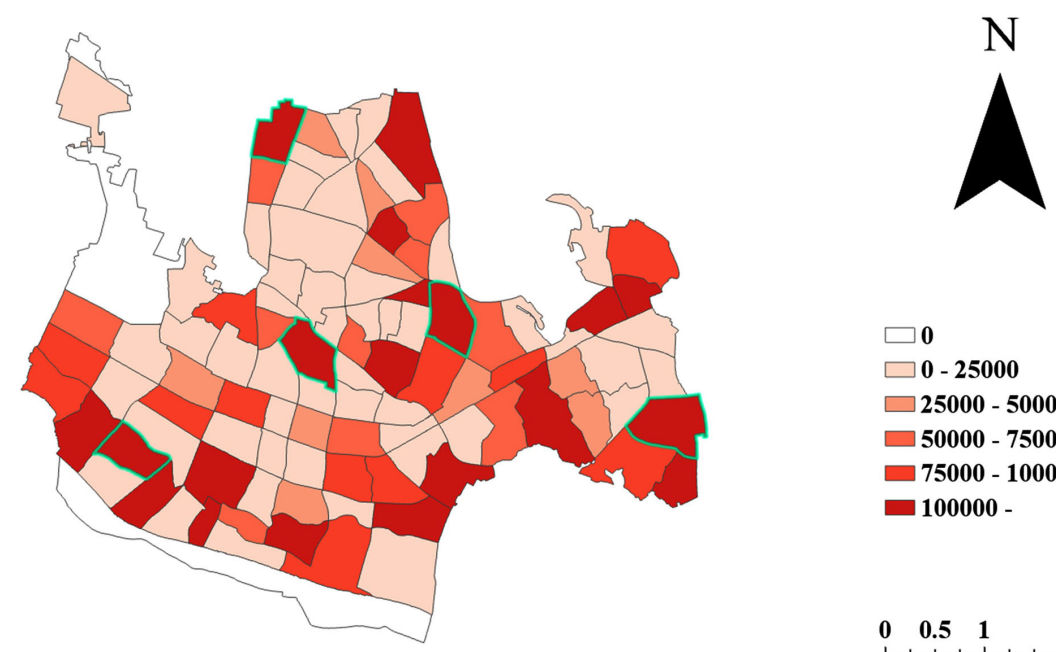

$\square \mathbf{0}$

$\square 0$ - 25000

$\square 25000-50000$

$\square \mathbf{5 0 0 0 0}$ - 75000

75000 - 100000

100000 -

$\begin{array}{lll}0 & 0.5 & 1\end{array}$ 2 km

Figure 8. Evaluation results when using specialization coefficients. 

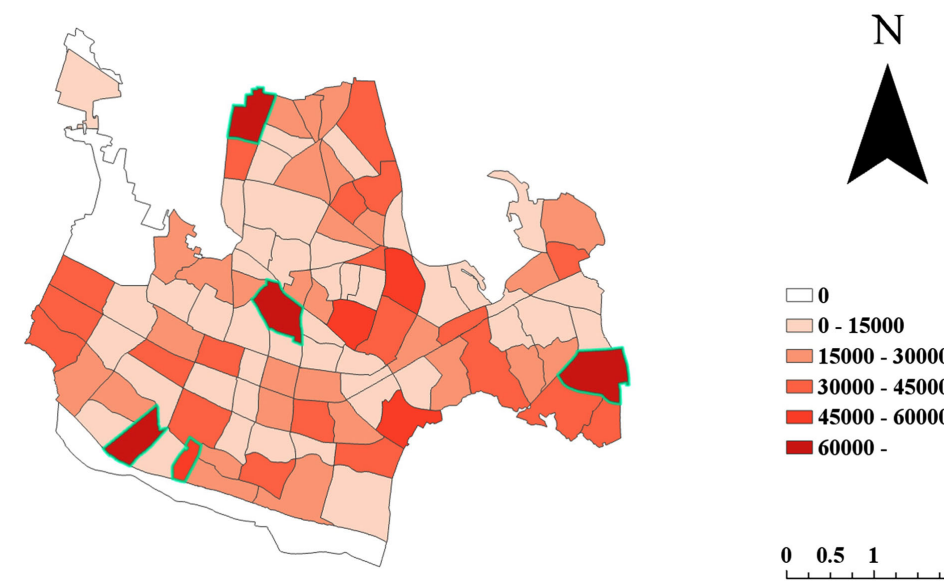

Figure 9. Evaluation results when the specialization coefficient was not used.
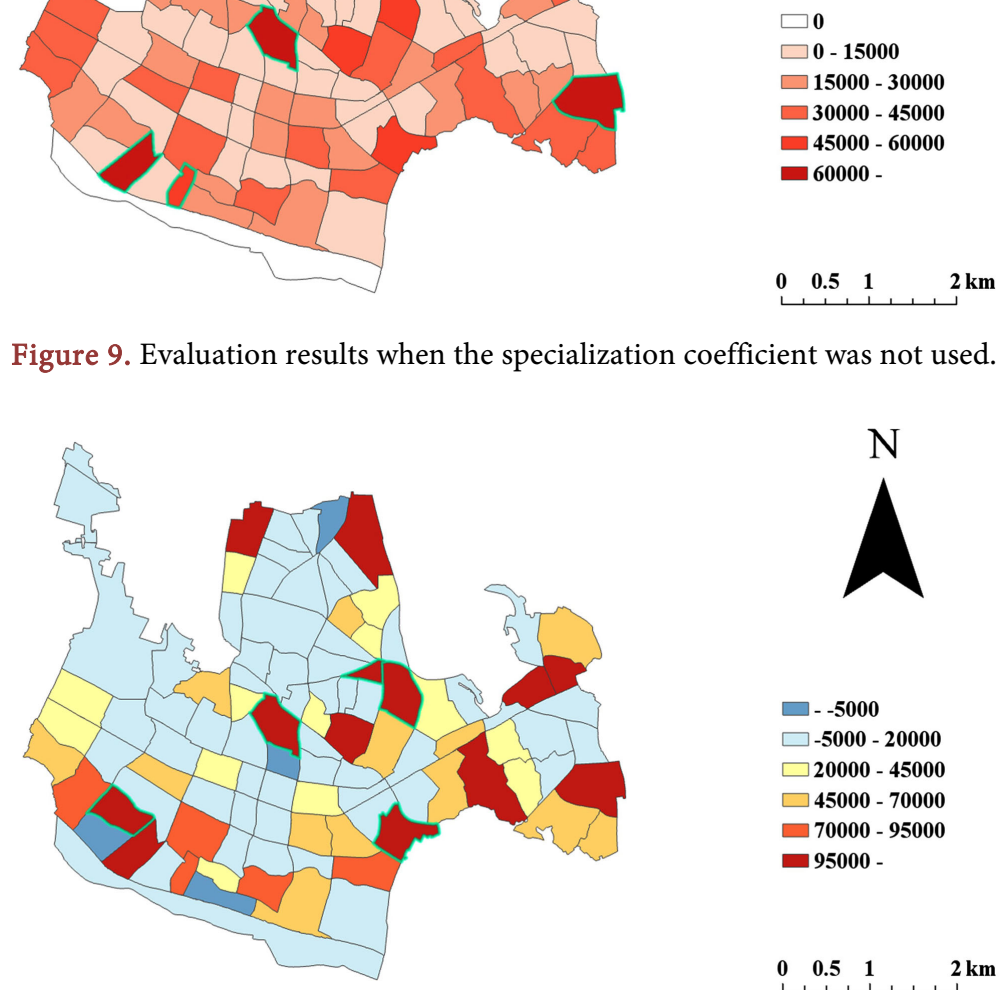

Figure 10. Difference between evaluation results with and without the specialization coefficient.

\subsection{Extracting Districts Lacking Facilities}

Based on the evaluation results in section 5.1 (the evaluation results for cases with the specialization coefficient), 5 districts with especially high evaluation points will be extracted as districts lacking facilities. The 5 districts outlined in light blue as shown in Figure 8 are districts with especially high population of infants and toddlers, and it can be said that these districts are currently lacking childcare facilities.

\section{Conclusions}

The conclusions of the present study can be summarized in the following 4 points.

1) In the present study, the model for the $p$-median problem that derives the optimum location for facilities was modified and a method to quantitatively evaluate the current location of childcare facilities in Japanese urban areas was proposed. The specialization coefficient of person trip for transportation used for the weighted distance was calculated from the person trips for the transpor- 
tation of infants and toddlers and their guardians, and could be effectively utilized as it took into consideration the load of the guardians. Thus, the evaluation method using specialization coefficients is dedicated to childcare facilities.

2) With the evaluation method, as evaluations are conducted using quantitative data such as the specialization coefficient of person trips for transportation and the distance between childcare facilities and districts, the evaluation results are also quantitative, making it an effective indicator for evaluating the location of childcare facilities. Furthermore, as the current location of childcare facilities is evaluated according to each district, it is easily possible to conduct the comparison of excess and deficiency in childcare facilities with other districts as well as the extraction of districts that lack childcare facilities. Additionally, as evaluation results are displayed on digital maps using GIS, the excess and deficiency trend of childcare facilities can be visually understood.

3) Regarding the evaluation method, the scenario analysis was used to select transportation. The scenario analysis is a method that analyzes how output is affected when multiple input factors are changed. Therefore, adopting the proposed evaluation method, it is possible to simplify the concept of the calculation of specialization coefficients using data of person trips reflecting time and transportation methods, which is suitable for the purpose of the present study. However, because the person trip data is the data of each region which is a group of several districts, person trips for each district were calculated in a complex manner described in section 3. Therefore, if more detailed person trip data is obtained, it is possible to increase the accuracy of the evaluation in the present study.

4) In the present study, the specialization coefficient of person trip for transportation and the distance between childcare facilities and districts were calculated based on public open data such as the National Census. As evaluations are conducted based on public information, by obtaining population data and geospatial data similar to the present study, evaluations can be conducted using data in other areas as well as for the past and future. Therefore, the evaluation method in the present study has a high temporal reproducibility as well as spatial reproducibility.

For future research subjects, the improvement of the evaluation method for cases where there are multiple facilities within a certain range as well as the application of the evaluation method of the present study in the evaluation of other facility locations and other areas can be considered.

\section{Conflicts of Interest}

The authors declare no conflicts of interest regarding the publication of this paper.

\section{References}

[1] Ministry of Health, Labour and Welfare (2017) Report on the Situation Related to Nursery Schools. Tokyo.

[2] Umezawa, A. and Kishimoto, T. (2003) Analysis of the Situation and Planning Op- 
timum Location of Nurseries in Metropolitan Areas. Summaries of Technical Papers of Annual Meeting Architectural Institute of Japan. F-1, Urban Planning, Building Economics and Housing Problems, 999-1000.

[3] Segawa, S. and Sadahiro, Y. (1996) A Decision-Making Support System for Child Care Facilities Using GIS. Theory and Applications of GIS, 4, 11-18.

[4] Sakaki, K., Miyake, T., Satoh, M., Satoh, E. and Mitsuhashi, N. (2014) Studies on the Deployment Plan of Childcare Facilities as Seen from Transportation, Commuting Behavior: Study of Facility Location That Was the Case Nikko Imaichi Region and Regions Nikko Fujiwara Region. Summaries of Technical Papers of Annual Meeting Architectural Institute of Japan (Rural Planning), 93-94.

[5] Kukimoto, M., Wakabayashi, Y. and Yui, Y. (2012) Production of Local Childcare Culture in Okinawa and the Impact of Policy Change. Geographical Review of Japan Series B, 84, 60-70.

[6] Fuse, M., Goda, M. and Inasaka, A. (2013) 5141 A Study on Reorganization of Childcare Facilities in Urban Area: Part 1. Potentiality of Conversion of Vacant Classroom of Public Schools in Adachi Ward. Summaries of Technical Papers of Annual Meeting Architectural Institute of Japan (Architectural Planning), 305-306.

[7] Furumido, N., Kaga, A. and Takeda, H. (2015) A Study on Behavioral Traits to Welcome and Send Their Children off to Day Nurseries and Child Rearing Value Scale in Two-Income Households. Journal of the City Planning Institute of Japan, 50, 761-767.

[8] Arami, R. (2017) What Causes Inequalities in Supporting Childcare Needs? Evidence from Variations in Local Childcare Policy in Japan. Tokyo.

[9] Langford, M., Higgs, G. and Dallimore, D.J. (2018) Investigating Spatial Variations in Access to Childcare Provision Using Network: Based Geographic Information System Models. Social Policy Administration. https://doi.org/10.1111/spol.12419

[10] Nagashima, T., Shinzato, T. and Kaku, I. (2014) Facility Location Problem of Quick Electric Recharging System for Electric Vehicles. Journal of Japan Industrial Management Association, 64, 557-560.

[11] Ozgen, D. and Gulsun, B. (2014) Combining Possibilistic Linear Programming and Fuzzy AHP for Solving the Multi-Objective Capacitated Multi-Facility Location Problem. Information Sciences, 268, 185-201.

https://doi.org/10.1016/j.ins.2014.01.024

[12] Munemasa, Y., Honda, Y. and Imai, K. (2015) Constrained Optimum Arrangement Structure Which Minimizes Travel Cost of Residence and Jobs. Journal of Architecture and Planning, 80, 1373-1380.

[13] Tanaka, K. and Furuta, T. (2015) Quintile Share Ratio in a Linear City with One and Two Facilities. Journal of the City Planning Institute of Japan, 50, 628-635.

[14] Tanaka, K. and Furuta, T. (2016) Evaluating Inequality of Facility Location in a Linear City Using Median Share Ratio. Journal of the City Planning Institute of Japan, 51, 894-900.

[15] Furuta, T. and Tanaka, K. (2017) Minimizing Quantiles Share Ratio in Multiple Facility Location Problem with Total Distance Constraint. Transactions of the Operations Research Society of Japan, 60, 36-49.

[16] Tsukahara, K. and Yamamoto, K. (2017) A Proposal of the Method to Evaluate the Location of Nursing Facilities Using Median Share Ratio. Papers and Proceedings of the Geographic Information Systems Association of Japan, 26, 4.

[17] Zhang, Y., Snyderc, L.V., Ralphs, T.K. and Xue, Z. (2016) The Competitive Facility 
Location Problem under Disruption Risks. Transportation Research Part E: Logistics and Transportation Review, 93, 453-473. https://doi.org/10.1016/j.tre.2016.07.002

[18] Ohdate, S., Tsunoda, M. and Yi, S. (2017) A Study on Phased Optimization of the Gross Area of Public Facilities via Facility Relocation: Verification of the Evaluation Process and Case Studies in Machida-City. Journal of Architecture and Planning, 82, 363-370. https://doi.org/10.3130/aija.82.363

[19] Nagai, H. and Kurahashi, S. (2017) Bustle Changes the City: Facility for Stopping Off and Modeling Urban Dynamics. Transactions of the Japanese Society for Artificial Intelligence, 32, D-G26_1-10.

[20] Usui, H. and Hino, K. (2018) Continuous Walking Distance and Criteria for Density of Resting Places: Application to Tokyo Central Station and Otemachi Station. Journal of Architecture and Planning, 83, 1049-1056.

https://doi.org/10.3130/aija.83.1049

[21] Tahara, S. and Osaragi, T. (2008) Effects of Commuting Distance and Direction on Choise Behavior of Nursery and Kindergarten. Summaries of Technical Papers of Annual Meeting Architectural Institute of Japan (F-1: Urban Planning, Building Economics and Housing Problems), 425-426.

[22] Takase, T. (2011) Kindergarten and Nursery Center Choice Behavior Analysis by Parents of Their Preschool Children in Nagano City. Journal of Japan Society of Civil Engineers, 67, 361-367.

[23] Grengs, J. (2011) Nonwork Accessibility as a Social Equity Indicator. International Journal of Sustainable Transportation, 9, 1-14. https://doi.org/10.1080/15568318.2012.719582

[24] Thakuriah, P., Soot, S., Tilahun, N., Vassilakis, W. and Cottrill, C. (2011) Analysis of Employment Transportation Services for the Job Links Program. Technical Report of Community Transportation Association of America, Chicago.

[25] Tatsumi, H., Tsutusmi, K. and Kouguchi, E. (2012) Characteristic Travel Behavior of Women with Infants of Toddlers Using Person Trip Survey Data. Journal of Japan Society of Civil Engineers, 68, 583-588. https://doi.org/10.2208/jscejipm.68.I_583

[26] Izumi, N., Hirata, S., Ishigami, T. and Matsui, H. (2012) Basic Analysis of Traffic Properties of Child Care Households in the Tokyo Metropolitan Area. Infrastructure Planning Review, 46, 4.

[27] Ohmori, N. (2015) Mitigating Barriers against Accessible Cities and Transportation, for Child-Rearing Households. International Association of Traffic and Safety Sciences, 38, 116-124. https://doi.org/10.1016/j.iatssr.2015.02.003

[28] Suzuki, A., Suzuki, W. and Kurita, A. (2015) Study on Accessibility Measures to Child Care Centers Applying Matching Theory: For Midori Ward, Nagoya as Subject Area. Journal of Japan Society of Civil Engineers, 71, 375-385. https://doi.org/10.2208/jscejipm.71.I_375

[29] Marinrique, Ruiz L.C. (2014) Proposal of an Evaluation Method of a Compact City Model. Ph.D. Thesis, University of Electro-Communications, Tokyo.

[30] Yabe T. (2016) Present Situation of Road Network. Transport Policy in Perspective, 2016, 48-49.

[31] (2018) Chofu City: A Survey on the Nursing Scools in Chofu City. http://www.city.chofu.tokyo.jp/www/genre/0000000000000/1277357583869/index.h $\underline{\mathrm{tml}}$ 